\title{
ANÁLISE DA EVAPOTRANSPIRAÇÃO E ÍNDICE DE ÁREA FOLIAR NUMA CULTURA DE SOJA SOB DOIS SISTEMAS DE MANEJO.
}

\author{
Virnei S. Moreira ${ }^{1,{ }^{*}}$, Débora R. Roberti ${ }^{2}$, Andréa U. Timm ${ }^{3}$, Geovane Webler ${ }^{2}$, \\ Gervásio A. Degrazia ${ }^{2}$ \\ ${ }^{1}$ Universidade Federal do Pampa/UNIPAMPA, Itaqui, RS, Brasil \\ ${ }^{2}$ Departamento de Física/UFSM, Santa Maria, RS, Brasil \\ ${ }^{3}$ Faculdade da Serra Gaúcha, Caxias do Sul, RS, Brasil \\ *virneimoreira@unipampa.edu.br
}

\section{RESUMO}

Neste trabalho são analisados resultados da evapotranspiração (ET) e do índice de área foliar (IAF) obtidos durante a estação de cultivo (2009/2010) para os sistemas de plantio direto (PD) e plantio convencional (PC) no ciclo da cultura da soja, no município de Cruz Alta, Rio Grande do Sul (RS).

\section{INTRODUÇÃO}

O conhecimento da água perdida por evapotranspiração é fundamental para se conhecer o balanço hídrico de certa região. A partir da disponibilidade hídrica, pode-se então determinar se essa região é indicada para o cultivo de determinada espécie vegetal ou se é necessário o uso de irrigação.

A complexidade na mensuração da (ET) se deve principalmente à difícil diferenciação aos processos de evaporação e transpiração que ocorrem na natureza (Allen et al., 1998). Em uma área agrícola, por exemplo, a evolução no crescimento da cultura determina qual processo contribuirá mais representativamente para a ET. A técnica de covariância dos vórtices tem sido aplicada cada vez mais nos estudos relacionados às perdas por evapotranspiração em cultivos de soja (Suyker e Verma, 2009, Singer et al., 2010). Desta forma o conhecimento da ET em diferentes sistemas de manejos pode avaliar se existem diferenças significativas nas perdas de água entre os mesmos. 


\section{MATERIAL E MÉTODO}

As observações experimentais foram realizadas na Fundação Centro de Pesquisas Experimentais (CCGL TEC / FUNDACEP), em Cruz Alta - RS, Brasil. A montagem experimental consiste de uma matriz de $40 \mathrm{~m} \mathrm{X} 60 \mathrm{~m}$ parcelas dispostos em pares. O ciclo da soja no sítio experimental de Cruz Alta avaliada neste trabalho iniciou no dia 14 de Dezembro de 2009 com a semeadura. No dia 13 de Abril de 2010 ocorreu à maturação fisiológica, e a colheita foi realizada no dia 28 de Abril de 2010.

Os dados de fluxos de calor latente foram obtidos através da torre de Eddy Covariance, instalada em cada sistema de plantio, para estimar a (ET), os sensores foram instalados a uma altura de 2,5 m durante a época de cultivo da soja na safra 2009/2010. O (IAF) foi determinado a partir da coleta de quatro plantas distribuídas aleatoriamente em cada sistema de plantio. As folhas de cada planta foram retiradas e dispostas sobre uma área conhecida e fotografada, após isso escaneadas e processadas por um programa. Este sítio faz parte do projeto Sulflux (www.ufsm.br/sulflux).

\section{RESULTADOS E DISCUSSÕES}

O comportamento sazonal da ET diária para a soja nos dois sistemas de plantio apresenta diferenças pequenas nos estágios fenológicos, conforme apresentado na (Figura 1). 


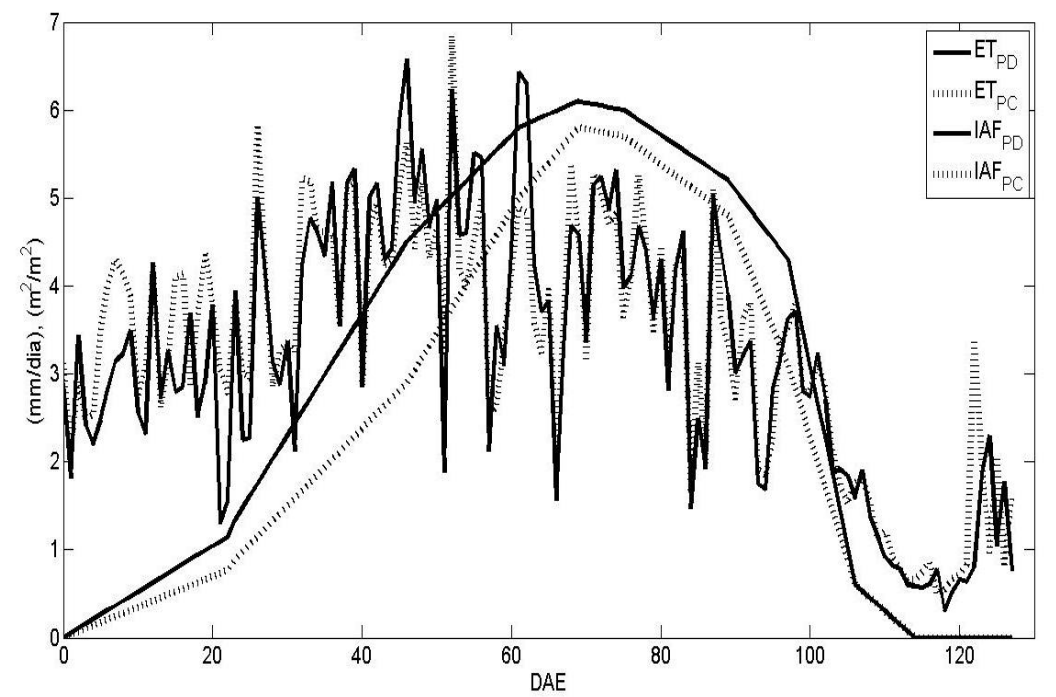

Figura 1 - Evapotranspiração e IAF nos sistemas: plantio convencional (PC) e plantio direto (PD).

Nos primeiros 30 DAE e no final do ciclo, nota-se que os valores da ET são ligeiramente menores para o $\mathrm{PD}$, possivelmente devido à presença de vegetação residual sobre o solo nú. Pois a cobertura morta também ajuda na redução da evaporação da água do solo através da diminuição da temperatura na superfície, elevando a disponibilidade de água no solo.

Autores como (Salton \& Mielniczuk, 1995) enfatizam que as perdas de água por evaporação são menores no plantio direto, devido à presença da camada de resíduos vegetais formando uma barreira isolante. Singer et al., (2010) retrata que durante a fase reprodutiva da soja, a transpiração representa de 89 a $96 \%$ da ET, indicando que o IAF influência fortemente a taxa de ET. Para o sítio experimental de Cruz Alta, a ET média da emergência à colheita (ciclo) foi de 3,20 mm / dia, para PD e ligeiramente maior para o PC, embora que no PD as fases vegetativas e reprodutivas a ET foi ligeiramente maior do que no PC. Apesar da proximidade espacial entre as duas parcelas, a forte influência do IAF na ET ainda pode ser reconhecida, e fatores como o tipo de vegetação, estágio de desenvolvimento da planta e forma de manejo da cultura também determinam como se dará a ET.

Conclusão

Os resultados encontrados no presente trabalho mostram que o (IAF) esta diretamente relacionada com a sua evapotranspiração. Analisando o fluxo de calor latente obtido nos dois sistemas de plantio, nota-se uma pequena diferença entre as 
medidas obtidas pelos mesmos, em média $2 \%$, porém ressalta um estudo mais aprofundado para analisar se existem realmente grandes diferenças nas medidas principalmente para grandes áreas agrícolas.

\section{BIBLIOGRAFIA}

ALLEN, R.G.; PEREIRA, L.S.; RAES, D., SMITH, M. Crop evapotranspiration. Guidelines for Computing Crop Water Requirements. FAO Irrigation and Drainage, Paper 56, FAO, Rome, 1998

LAMARI, L. Assess 2.0: Image Analysis Software for Plant Disease Quantification. Department of Plant Science, University of Manitoba, Winnipeg, Canada. The American Phytopathological Society. 2008.

SUYKER, A.E.; VERMA, S.B. Evapotranspiration of irrigated and rainfed maizesoybean cropping systems. Agricultural and Forest Meteorology, v.149, p.443452, 2009.

SALTON, J.C.; MIELNICZUK, J. Relações entre sistemas de preparo, temperatura e umidade de um Podzólico Vermelho-Escuro de Eldorado do Sul (RS). Revista Brasileira de Ciência do Solo, v.19, p. 313-319, 1995.

SINGER, J.; HEITMAN, J.L.; HERNANDEZ - RAMIREZ, G.; SAUER, T.; PRUEGER, J.H.; HATFIELD, J.L. Contrasting methods for estimating evapotranspiration in soybean. Agricultural Water Management, v.98, p.157-163, 2010. 